\title{
Consumption and the Indian Diaspora: A Study of Jhumpa Lahiri's The Namesake
}

\author{
Rashmi Das \\ Ph.D. Research Scholar, Dept. of English, Tezpur University, Assam, India. \\ ORCID ID: oooo-0oo2-2322-9049. Email: rashmidaso94@gmail.com
}

\begin{abstract}
For the diaspora, consumption remains a significant exercise, as it acts as a means of appropriation of the host land, while also being an agency of assimilation and categorisation. Moreover, the fact remains that consumption or eating simultaneously entails regeneration and violence. As such, this paper justifies how the locus of consumption is multifaceted, being not only physical, but also metaphorical, and at times hyperreal, whereby the diaspora exists not only as consumers, but also as an item of consumption by the hosts. For this purpose, Jhumpa Lahiri's The Namesake (2003) has been analysed through the methodology of close reading, to present how food and its narrative is used as a repetitive metaphor and an ideological implement, which further illuminates the technicalities of consumption among the Indian diaspora. To set the stage, this paper briefly summarises the development of food studies as a genre, which has successfully enlarged the scope of literary criticism and research. Theoretically, this paper draws on Mikhail Bakhtin's discourse of food and eating as presented in his work Rabelais and His World (1965). By examining the unifying trope of food, this paper attempts to study the numerous dichotomies between the diasporic body and the concept of the grotesque body, as put forward by Bakhtin. This paper also attends to the concept of "culinary citizenship" (Mannur, 2010, p. 20) and traces the way it is overturned in favour of culinary "interorientation" (Bakhtin, 1965/1984, p. 317).
\end{abstract}

Keywords: Consumption, Food, Diaspora, Culinary citizenship, Culinary interorientation, Banquet, Inverted exoticism.

\section{Introduction}

That food and literature have a long-standing relation can no longer be denied or brushed under the carpet. Although food imageries were ever-present in works of literature, literary food studies has only recently achieved the much needed scholarly attention. Food has remained a major area of study among the anthropologists and sociologists, but from the 196os onwards, the rise of semiotic studies helped to legitimatise food studies as an important genre. As an interesting outcome, food studies gained much impetus from the domains of sociology, cultural studies, history, philosophy, structuralism, classicism, psychology and literature (Avakian \& Haber, 2005, pp. 3-4). The figurative usage of culinary symbols, contexts and images, as well as vivid or even subtle alimentary descriptions, facilitates fictional writers to creatively express their ideas and drive the action of their plots. Literary food studies represent the smaller details of life, and even tend to highlight the low cultures and the grotesque forms, which occupy a considerable space in human society. The intermingling of the aforementioned disciplines have extended the orbit of literary researchers (Counihan \& Esterik, 2013, pp. 1-3), as food no longer remains a mere alimentary

(c) AesthetixMS 2021. This Open Access article is published under a Creative Commons Attribution Non-Commercial 4.0 International License (http://creativecommons.org/licenses/by-nc/4.o/), which permits non-commercial re-use, distribution, and reproduction in any medium, provided the original work is properly cited. For citation use the DOI. For commercial re-use, please contact editor@rupkatha.com. 
compound but extends into what Roland Barthes defines as "a system of communication, a body of images, a protocol of usages, situations, and behavior" (Barthes, 1961/2013, p. 24).

Explaining the act of consumption Mikhail Bakhtin in his book, Rabelais and His World (1965) suggests that, eating allows the transgression of bodily limits, to swallow and devour the world, thus making it a part of oneself. This way, the consumer effectively grows at the world's expense (Bakhtin, 1965/1984, p. 281). Bakhtin further adds that the very act of consumption puts one's attention beyond the body's limited space, into the body's depths (Bakhtin, 1965/1984, p. 318). As such, it plays an important role in making us who we are, because the type of food we prefer and manage to eat, goes a long way in the formation of our personality. Additionally, Claude Levi Strauss in his classic structuralist article, "The Culinary Triangle" (1966), equates cooking to language, as the preparation of food remains a "truly universal form of human activity" (Strauss, 1966/2013, p. 40), by dint of which it unconsciously translates its structure or may even unconsciously reveal its contradictions (Strauss, 1966/2013, p. 47). This is when food becomes an implement or a tool through which ideological hegemony and other cultural constructs can be subtly circulated among people $(\mathrm{Xu}, 2008, \mathrm{p} .4)$. Therefore, when the diaspora transgresses its physical and national boundaries, and encounters the rubrics of life in a strange land, consumption or eating acts as one of the most frequent and meaningful exercise. To flourish in a strange land, the diaspora has to continuously move between the activities of assimilation and categorisation, tasks in which the choice of food, the manner of cooking and even the act of eating, play a subtle but intense, and almost an invasive role. Eating being a natural necessity, becomes an effective medium through which the diaspora can hold on to their sense of identity, and with time learn to add new dimensions to their identities. Thus, the very acts of cooking and consumption are transformative and when examined carefully can transmit powerful messages.

To the untrained observer such attention to food may seem a mundane and even an unnecessary task, but food scholars like Mary Douglas (1972), Jennifer Ann Ho (2005), Wenying Xu (2008), Mannur (2010) William R Dalessio (2012), to name a few, have proved just how right and essential this venture actually is. Being a non-verbal presence, food ensures that its consumption remains ambivalent, and thus possibly endowed with rich meanings, which necessarily calls for its careful examination. The ideas that literary works express through food can be considered a part of what Sara Littlejohn calls "food narratives" (Littlejohn, 2008, p. 1), as the major actions and events revolve around acts of preparation, consumption or even imagination. In such works, food often functions as a rhetorical device and an ideological implement, rather than an ornamental excess. It works rather intrinsically to persuade the fictional characters and readers alike, even while its visibility may be controlled, as per convenience.

\section{The Indian diaspora and the multivalence of consumption}

For the diaspora, food is another carrier of culture, among language, rhythm and so on, and "cuisine like religion, is one of the sites where the migrant turns away hesitatingly from the embrace of the metropole", or the hostland (Ray, 2004, p. 1). As such, food has always remained a subtle yet an appropriate tool, and the culinary- a vital site- through which one can critique the complex diasporic experiences and dilemmas. The fragmented entity of the diaspora is reflected in their understanding of food as a portal through which they seek to re-establish their ethnic histories, cultural identities and sense of community in a displaced world. Food functions as an effective gastronomic zone and an "emotional anchor" (Mannur, 2010, p. 27), whereby issues such asnostalgia, the resultant creation of hybrid dishes and hybrid identities, shocks of arrival as of return, attempts at cultural preservation through culinary recreation, fluidity of ethnicity, clash between generations- are effectively staged (Mannur, 2010; Pazo, 2014). The rise of multiculturalism has 
revealed how food can be used as a political instrument of fusion, which further enhances exoticism, racism, fear and anxiety against ethnic minorities (Ho, 2005; Xu, 2008; Mannur, 2010). Therefore, as food gets intrinsically related to our identities, there arise numerous issues of racism. Most visibly, ethnic eaters, for example the Asian immigrants, are discriminated by the majorities of their western counterparts in the host-lands. This stereotype however is now being constantly challenged, thanks to the literary food critics like Mannur, $\mathrm{Xu}$ and Dalessio, who strive to prove how we are not what we eat, because our choice of food at a particular time, may differ according to contexts such as availability, feasibility and so on.

Additionally, consumption is not merely limited to physical ingestion but extends to other levels such as the metaphorical and even the hyperreal. Explaining hyperreal consumption Mannur says that at this level, one can eat even without eating (Mannur, 2010, p. 84). Therefore, to add to V. N. Voloshinov's study of sign and ideology, it can be said that not only "any item" of consumption, but the very act of consumption itself can become a sign whose meaning extends beyond its particular context (Voloshinov, 1930/1973, p. 10). This is why consumption is never linear but multivalent, and always ideological. While studying the critical entity of the Indian diaspora the manner of consumption frequently emerges as a prevalent source of stereotype which propagates "one-dimensional portraits of Asians as cooks, waiters, and other fetishized objects of mainstream consumption" (Ho, 2005, p. 3). Moreover, their oppressive colonial baggage which made them choose their site of autonomy from a subordinate position, heavily impacts the diaspora's daily existence. This results in their deep connection to food and culture, and, extends to the enactment of what Mannur conceptualises as culinary citizenship (Mannur, 2010, p. 20). It provides the diaspora a facility to "claim and inhabit certain identitarian positions via their relationship to food", which makes the process of assimilation even harder (Mannur, 2010, p. 29). Indian English novels such Anita Desai's Fasting, Feasting (1999), Jhumpa Lahiri's The Namesake (2003), Manju Kapur's The Immigrant (2008), Amitav Ghosh's River of Smoke (2011) and Flood of Fire (2015), Kiran Desai's The Inheritance of Loss (2006) and Amulya Malladi's The Mango Season (2003), among others, present previously unregistered experiences of the diaspora and also attends to the complexities involved in the diaspora's return to the homeland.

\section{The trope of consumption in The Namesake}

Jhumpa Lahiri's The Namesake can otherwise be grouped under the banner of yet another diaspora narrative, but when looked through the angle of food, it reveals Lahiri's fresh consideration of the multivalence of consumption and the diasporic body. Routing through the perspectives of both the first and second generation of immigrants, Lahiri represents how they can never fully belong to either countries. The act of the juxtaposition of cultures is presented from the very beginning as we are introduced to the dislocated immigrant, Ashima. Representing the stereotypical South Asian female subjectivity, she stands in her Cambridge kitchen attempting to exercise her culinary citizenship, through an imperfect recreation of the favourite Bengali snack jhalmuri. While she thus prepares to gastronomically revisit the nostalgic taste of home, she is immediately jolted back to her present reality, due to the lack of a certain taste she desires, and also by the second generation immigrant- the yet to be born Gogol. Ashima's pregnancy in the foreign land further symbolises an eternal pregnancy on the part of the immigrants- "a perpetual wait, a constant burden, a continuous feeling out of sorts" (Lahiri, 2003/2018, p. 49). While her pregnancy symbolises the gendered experience of the diaspora (Karmakar, 2019/2020, p. 45), it also effectively captures the duality of diasporic identities, by being symbolic of the ever-creating "dual body" (Bakhtin, 1965/1984, p. 256). Gogol's birth initiates their communication with the outer world and marks the transition from the confines of the old towards an adjustment to, and "interchange" (Bakhtin, 1965/1984, p. 317) with 
the new. It results in the bodily transgression of their own limits as they grow and attempt to merge into their adopted land.

The opening scene very well gives a premonition about what to expect throughout the novel, such as, the clash between immigrant generations, or even the perpetual inevitability of there being "something missing" (Lahiri, 2003/2018, p. 1). Broadly speaking, the novel presents the inheritance of homelessness through its poignant portrayal of a privileged family of immigrants from India. Lahiri's concept of ever-present homelessness critiques and problematises, "the comforts of the diasporic home, and encourages us to think about the political significance of the altered meanings of privilege, home, and postcoloniality" (Malik, 2016/2017, p. 58). There is a sustained employment of polyphonic voices (Chandorkar, 2017, p. 207) in her works, which combined with maternal aesthetics (Karmakar, 2019/2020, p. 45) as in The Namesake, poignantly illuminates the nagging diasporic dilemma, of whether to belong or to categorise. As for the second generation immigrants, the novel underlines the fact that the idea of a "home country" remains "fallacious" as the fluidity of their identity is constantly foregrounded (Friedman, 2008, p. 115). The novel is an exemplum of tiding over the "anti-modern" idea of "ethnic absolutism", whereby migrants choose to remain in their "fantasy structures of homeland" instead of considering the process of assimilation (Mishra, 2007, p. 17). However, the second generation diaspora, being "perennial migrants", with no pre-determined national allegiance, has to voluntarily assimilate in the adopted land (Friedman, 2008, p. 113). Basically, the story revolves around the strange name that is given to Gogol, which is a constant source of embarrassment and serves to emphasise his otherness, thereby marking his awkward position in America. It is remarkable that the name chosen for him is "lost in transit", symbolically foretelling his loss of belongingness (Heinze, 2007, p. 194). Ironically, the name "Gogol" is chosen by his parents to get their release from the hospital, but in the very act, they entangle themselves in a problematic future.

What runs as a unifying and interesting thread in the novel is the constant reference to food in respect to banal as well as special occasions. As Lahiri peppers her narrative with the labour surrounding food preparation, and its actual and symbolic consumption, the diasporic complexity attends further realism. Dietary images play a crucial role in driving the action of the narrative and provide us with an internal view of the characters' perception. The novel represents Ashima in particular, and mothers in general, as negotiators of culture, for whom being diasporic is a challenging process as it is laden with gendered expectations (Karmakar, 2019/2020, p. 53). In such cases, as duly presented in the novel, immigrants often seem to resist isolation through cooking and consumption, which facilitate a mode of belonging at once to the original nation and the adopted land. Mannur terms such women as cultural brokers, "whose bodies and lives have been drawn by their labor within food preparation" (Mannur, 2010, p. 137).

In a novel departure, Lahiri juxtaposes the concept of hyperreal consumption of immigrants, to that of the immigrant's perception of the hosts, through the triple narratives of Ashoke, Gogol and Moushumi. Ashoke's adolescence in India was nurtured by his hyperreal consumption of foreign literary works, which paved the way for his future settlement in America. As Ashoke exoticises the story of Akaky Akakyevich, he experiences an alternate ingestion of foreign foods such as "cold veal and cream pastries and champagne", things that "Akaky consumed the night his precious coat was stolen, in spite of the fact that Ashoke had never tasted", nor probably seen these things himself (Lahiri, 2003/2018, p. 14). This is an example of inverted exoticism where Ashoke acts as the consumer of Russian culture. His admiration of, and obligation to Nikolai Gogol, also manifests in his naming his son, Gogol, which later engulfs them in a troubled relation. 
Similarly Gogol and Moushumi are also consumers of foreign cultures, as through their numerous relationships with people from different ethnic backgrounds, they embark on a hyperreal "gastronomic tour" (Friedman, 2008, p. 119). Here food plays a revelatory role, along with its obviously aphrodisiac role, as Gogol begins to appreciate the scarce food items served at Maxine's house:

a thin piece of steak rolled into a bundle and tied with string, sitting in a pool of dark sauce, the green beans boiled so that they are still crisp. A bowl of small, round, roasted red potatoes is passed around, and afterward a salad. (Lahiri, 2003/2018, p. 133)

Although meagre, Gogol treasures the relaxed and "indulgent ritual of the lingering meal" (Lahiri, 2003/2018, p. 134) and quite consciously compares it with the painfully formal dining culture of his home, especially when guests drop by:

His own mother would never have served so few dishes to a guest. She would have kept her eyes trained on Maxine's plate, insisting she have seconds and then thirds. The table would have been lined with a row of serving bowls so that people could help themselves. (Lahiri, 2003/2018, p.133)

Steeped within Gogol's appreciation of Maxine's privileged American life, is the quite reference to "the violence of postcolonial loss and an epitome of American success riddled with the certainty of provincialism and racial marginalization" (Malik, 2016/2017, p. 55). The trauma of the postcolonial loss, their tentative belongingness (Malik, 2016/2017, pp. 55-56), combined with the lingering nostalgia and a lack of confidence, is bound to reduce them to "caterers in their own home, solicitous and watchful" in the presence of guests or outsiders (Lahiri, 2003/2018, p. 141).

Similarly Moushumi's extramarital affair with Dimitri is cleverly narrated through the aphrodisiac foods that they consume, almost as a fixed ritual before consuming each other: "poached fish; creamy potato gratins; golden, puffed chickens roasted with whole lemons in their cavities", followed by wine, coffee, cognac and cigarettes (Lahiri, 2003/2018, p. 263). Their elegant food choices seemingly enhance and solidify Moushumi's choice to inhabit and remain in her third space, a space that not only allows the unquestioned existence of her hybrid identity, but also satisfies her hyperreal cravings, which has remained unrealistic in her marriage. In Gogol and Moushumi's respective affairs, it is interesting to note that the different modes of consumption always remain in the spotlight. Their hunger for white bodies is a part of their assimilative strategies and symbolises a rebellion towards their ethnicity. Their curiosity rather borders on the verge of voyeurism, as the narrator alternatively sketches their white partners in exotic colours, to be ultimately consumed by the immigrant bodies (Friedman p.121). Nevertheless, the novel makes it evident that Ashoke, Gogol and Moushumi are also simultaneously swallowed up by the very cultures that they admire and try to mirror.

A proper analysis of such acts of hyperreal consumption, or even the detailed description of Ashima's pregnancies, calls for an application of the Bakhtinian viewpoint as put forward in the book Rabelais and His World (1965). Diasporic bodies are quite similar to the grotesque body, which being in an eternal state of flux or "becoming" (Bakhtin, 1965/1984, p. 317), underlines the "fluid movement between attraction and repulsion, compassion and disgust, humour and horror, materiality and mystery" (Journey, 2014, p. 15). Such endless dichotomies, which acquire much prominence among the diaspora, are properly staged via the trope of mutual cultural consumption, an iterative process, "through which enters the world to be swallowed up" (Bakhtin, 1965/1984, p. 317). Adjustment and approximation of the new land, or even of the immigrant bodies, require intermingling or so to say "an interchange and an interorientation" (Bakhtin, 1965/1984, p. 317) to 
overcome the constraints of both the cultures. Thus while Ashima works her best to preserve her ethnic identity through the exercise of her "culinary citizenship" (Mannur, 2010, p. 20), cultural dilution is invariably on its way as she experiences "cultural and geographical fluidity by the very practice of her life through the decades" (Assadnassab, 2012, p. 12). Culinary interorientation replaces her culinary citizenship, as she learns to cook familiar dishes from unfamiliar items such as making halwa from Cream of Wheat, tea from evaporated milk, yogurt from 'half and half, sandesh from ricotta cheese and so on.

The novel also presents numerous scenes of banquet, starting right from Gogol's annaprasan or rice feeding ceremony, "meant to introduce him to a lifetime of consumption" to the final celebratory goodbye meal that Ashima prepares for her children and her significantly enlarged circle of friends (Lahiri, 2003/2018, p. 40). Apart from the transmission and renewal of cultural messages, such communal feasts are representative of the "victory" of a privileged section of the Indian diaspora, as they settle and grow "at the world's expense", or so to say, thrive at the expense of the hostland (Bakhtin, 1965/1984, p. 283). These communal meals or banquets help the diaspora to pass around the knowledge of gastronomic hybridization, as the new immigrant wives, "homesick and bewildered, turn to Ashima for recipes and advice" on how to approximate the foreign atmosphere as well as the unfamiliar food items (Lahiri, 2003/2018, p. 38).

Lahiri has also made sure to include an episode of death, whereby she presents the compatibility of death and food, as suggested by Bakhtin (Bakhtin, 1965/1984, p. 283). Reflecting on Ashoke's death along with the death of their loved ones, Malik comments that "death permeates the very structure of the Gangulis' home, signaling the fragility, contingency, and reversibility of American racial assimilation and belonging" (Malik, 2016/2017, p. 55). However, at the same time it is worth noting that this very permeability is sought to be overcome by eating meals of consolation on behalf of the deceased. One can notice how Ashima and her children observe a "mourner's diet" for ten days, as they avoid meat and fish and instead find solace in bland vegetarian food (Lahiri, 2003/2018, p. 180). Shocked by Ashoke's demise, food becomes the only thing that structures their grieving days, and each evening, they are "strangely hungry" and "eager to taste the blandness on their plates" (Lahiri, 2003/2018, p. 181). When everything else seems meaningless, food remains the only agreeable thing, bearing the capability to reinstate a sense of assurance, seemingly saving them from further mental disintegration. Mealtimes are the only moments when their grief somewhat loses its intensity, as by their deliberate rejection of certain foods, they feel closer to Ashoke. The mourning period ends with a religious ceremony alongside a funeral banquet, where they prepare an "elaborate meal" of meat and fish, "cooked as his father liked them best, with extra potatoes and fresh coriander leaves" (Lahiri, 2003/2018, p. 181). With the house once again filled with the smells of familiar foods, they feel "as if it is just another party" that celebrates the victory and enlargement of Ashoke's life (Lahiri, 2003/2018, p. 181).

There is also the detailed description of Gogol's wedding banquet, but instead of providing "the potentiality of a new beginning" (Bakhtin, 1965/1984, p. 283), The Namesake goes on another interesting departure. Lahiri demonstrates a "leftover" (Lahiri, 2003/2018, p. 224) wedding with a typical north Indian fare, instead of a Bengali one, and awkward champagne toasts, that hardly has any future potentialities (Lahiri, 2003/2018, pp. 223-224). It is evident that instead of being "cultural correctives for one another", Gogol and Moushumi's relationship brings out their inadequacies and incompatibility as second generation immigrants (Bhalla, 2012, p. 116). Being past consumers of foreign bodies, their solace in each other is only momentary and marked by a persistent sense of lack and displeasure. By her presentation of their "leftover" wedding, Lahiri is able to truthfully 
present the fluidity of the diaspora. The new lease of hope is instead presented in Gogol and Ashima overcoming their insecurities towards being independent.

A celebration of their long and triumphant stay in America is marked by their final Christmas eve party, through which the narrative reflects on the growth of its characters. As Mannur rightly comments, Ashima's "final act of communion with the desi community is one that, unsurprisingly, centers on sharing food” (Mannur, 2010, p. 147). Lahiri's detailed focus on food images, combined with the effortful exercise of cooking lends a realistic charm to the novel, as the preparation of Ashima's special mincemeat croquettes is described:

First she forces warm boiled potatoes through a ricer. Carefully she shapes a bit of the potato around a spoonful of cooked ground lamb ... She dips each of the croquettes, about the size and shape of a billiard ball, into a bowl of beaten eggs, then coats them on a plate of bread crumbs, shaking off the excess in her cupped palms. Finally she stacks the croquettes on a large circular tray, a sheet of wax paper between each layer. (Lahiri, 2003/2018, p. 274)

The party reflects the scenes of banquet and serves to present what Bakhtin calls, "the true epilogue" containing "potentialities of the new beginning" as they gain perspectives in their lives (Bakhtin, 1965/1984, p. 283). Hereby the previous image of Ashima's subservient attitude towards her guests religiously waiting "until most of their guests' plates were stacked by the sink in order finally to help themselves" (Lahiri, 2003/2018, p. 141) is replaced with equivalence as she "looks forward to serving herself, sitting among her guests" (Lahiri, 2003/2018, p. 277). Further the painstaking mechanics of cultural recreation is replaced by its successive dismantling, as Ashima matures into a transnational person, deciding to divide her time between the homeland and the hostland. As for Gogol, he finally accepts his father's gift- The Short Stories of Nikolai Gogol- which signifies his coming to terms with his Indian-American identity, and a voluntary acceptance of the state of liminality. In short, the imagery of swallowing or consumption runs as an important parallel to the discourse of cultural interchange throughout the novel. As the diasporic body due to its constant motion becomes transgressive and hybrid, applying Bakhtin's theoretical proposition on the act of consumption in our reading, brings out the perpetual ambivalence of the diaspora, and, makes one actually comprehend what it means to be diasporic.

\section{Conclusion}

Lahiri mastered the representation of material body by magnifying its constant state of flux and of "becoming" (Bakhtin, 1965/1984, p. 317). The consistent trope of immigrant consumption adds depth to her fictional account. By portraying the immigrants as consumers of the hostland, she shows that diasporic bodies cannot be represented as "individualized and closed" as is the case with the new literary canon (Morris, 1994/2003, p. 227). Instead she presents how the diasporic bodies are open to interchange and interorientation, whereby they engage in a continuous and open ended dialogue of being and becoming. The novel represents how the constrictions of culinary citizenship are replaced by the subtlety of consumption, as its significance extends beyond its physical context. Thus the trope of consumption is multifaceted as it is not only limited to the physical act, but also extends towards metaphorical and hyperreal ingestion, where both the immigrant and the host engage in.

\section{References}


Assadnassab, A. (2012). Displacement, an Unknown Freedom: Cultural Identity in Jhumpa Lahiri's The Namesake.

Avakian, A., \& Haber, B. (Eds.). (2005). From Betty Crocker to Feminist Food Studies: Critical Perspectives on Women and Food. University of Massachusetts Press. Retrieved January 20, 2021, from http://www.jstor.org/stable/j.ctt5vk2tn

Bakhtin, M.M. (1984). Rabelais and His World. (Iswolsky Hélène, Trans.). Bloomington, US: Indiana University Press. (Original work published 1965)

Barthes, R. (2013). Toward a Psychosociology of Contemporary Food Consumption. In C. Counihan \& P. Van Esterik (Eds.), Food and culture: A reader (3rd ed., pp. 23-30). Routledge. https://doi.org/10.4324/9780203079751. (Original work published 1961)

Bhalla, T. (2012). Being (and Feeling) Gogol: Reading and Recognition in Jhumpa Lahiri's The Namesake. MELUS: Multi-Ethnic Literature of the U.S., 37(1), 105-129. https://doi:10.1353/mel.2012.0013

Chandorkar, L. (2017). The Indian Diaspora in America as Reflected in Jhumpa Lahiri's Fiction. History and Sociology of South Asia, 11(2), 204-211. https://doi.org/10.1177/2230807517701862

Counihan, C. \& Esterik, P.V. (Eds.). (2013). Food and culture: A reader (3rd ed.). NY: Routledge. https://doi.org/10.4324/9780203079751

Dalessio, W.R. (2012). Are We What We Eat? Food and Identity in Late Twentieth-Century American Ethnic Literature. Amherst, New York: Cambria Press.

Douglas, M. (1972). Deciphering a Meal. Daedalus, 101(1), 61-81. Retrieved March 23, 2021, from http://www.jstor.org/stable/20024058

Friedman, N. (2008). From Hybrids to Tourists: Children of Immigrants in Jhumpa Lahiri's The Namesake. Critique: Studies in Contemporary Fiction, 50(1), 111-128. https://doi.org/10.3200/CRIT.50.1.111-128

Heinze, R. (2007). A Diasporic Overcoat?. Journal of Postcolonial Writing, 43(2), 191-202. https://doi:10.1080/17449850701430598

Ho, Jennifer A. (2005). Consumption and Identity in Asian American Coming-of-Age Novels. New York, US: Routledge.

Journey, A. (2014). Earn the Vomit: Employing the Grotesque in Contemporary Poetry. The American Poetry Review, 43(5), 15-19. Retrived January 21, 2021, from http://www.jstor.org/stable/24593727

Karmakar, I. (2020). Being a Foreigner ... Is a Sort of Lifelong Pregnancy: Interrogating the Maternal and the Diasporic in Jhumpa Lahiri's The Namesake. Scrutiny2, $24(1), 44$ - 57. https://doi.org/10.1080/18125441.2019.1650821 (Original work published 2019)

Lahiri, J. (2018). The Namesake. Uttar Pradesh, India: Harper Collins. (Original work published 2003)

Littlejohn, S.J. (2008). The Rhetoric of Food Narratives: Ideology and Influence in American Culture [Doctoral dissertation, University of North Carolina-Greensboro]. NC Docks. https://libres.uncg.edu/ir/uncg/f/umi-uncg-1642.pdf

Malik, S. (2017). Homelessness as Metaphor and Metonym: Transatlantic Geopolitics in Jhumpa Lahiri's Fiction and Kiran Desai's The Inheritance of Loss. South Asian Review, 37(2), 47-70. https://doi.org/10.108o/02759527.2016.11933061 (Original work published 2016)

Mannur, A. (2010). Culinary Fictions: Food in South Asian Diasporic Culture. Philadelphia, PA: Temple University Press.

Mishra, V. (2007). The Literature of the Indian Diaspora: Theorizing the diasporic imaginary. New York, US: Routledge. 
9 | Consumption and the Indian Diaspora: A Study of Jhumpa Lahiri's The Namesake

Morris, P. (1994). The Bakhtin Reader: Selected Writings of Bakhtin, Medvedev and Voloshinov. London: Edward Arnold (Publishers) Ltd.

Pazo, P. T. (2014). Diasporic Tastescapes: Intersections of Food and Identity in Asian American Literature [Doctoral thesis, University of A Coruña]. CORE. https://core.ac.uk/download/pdf/61910855.pdf

Ray, K. (2004) The Migrant's Table: Meals and Memories in Bengali-American Households. Philadelphia, PA: Temple University Press.

Strauss, L. (2013). The Culinary Triangle. In C. Counihan \& P. Van Esterik (Eds.), Food and culture: A reader (3rd ed., pp. 40-47). Routledge. https://doi.org/10.4324/9780203079751 (Original work published 1966)

Voloshinov, V.N. (1973). Marxism and the Philosophy of Language (Ladislav Matejka \& I. R. Titunik, Trans.; 1st vol.). New York: Seminar Press. (Original work published 1930)

Xu, W. (2008). Eating Identities: Reading Food in Asian American Literature. Honolulu, USA: University of Hawai'i Press.

Rashmi Das is a Ph.D. Research Scholar, from the Department of English, Tezpur University, Assam, India. She is currently working on her thesis: 'Food Rhetoric and the Politics of Narration: A Study of Select Indian English Fiction'. Her research interest includes food studies, postcolonial literature, diaspora studies and Indian writing in English. 